\title{
A biotecnologia como instrumento de desenvolvimento econômico e social
}

\author{
Marcelo Gonçalves do Valle \\ Mariana dos Santos Santos ${ }^{2}$
}

\section{Resumo}

Este artigo analisou a biotecnologia como fonte de desenvolvimento social e econômico para o Brasil. A Cooperação Internacional é abordada como meio de se obter os recursos tecnológicos necessários para a aplicação deste instrumento. Por esta razão, efetuou-se uma análise da Cooperação Técnica Internacional, uma das vertentes da cooperação mais importante e evidente. O trabalho aponta que o Brasil vislumbra oportunidades para impulsionar o seu desenvolvimento por meio da biotecnologia com a recente Política de Desenvolvimento de Biotecnologia e a criação do Comitê Nacional de Biotecnologia. A análise do Centro Brasileiro Argentino de Biotecnologia (CBAB) demonstra empiricamente a importância da cooperação para incentivar o uso da biotecnologia nos países do sul e, com efeito, acelerar o desenvolvimento nesses lugares. No entanto, a dificuldade encontrada pelo Brasil baseia-se na ausência de interação entre os setores acadêmicos e científicos e os setores produtivos.

Palavras-chave: Biotecnologia. Desenvolvimento. Cooperação Internacional. Cooperação Sul-Sul. Cooperação Empresa-Universidade.

\section{Introdução}

A biotecnologia é marcada pela conjugação de um "bloco de conhecimentos" (building block) que combina protocolos de pesquisa já existentes com novos

\footnotetext{
${ }^{1}$ Professor de Relações Internacionais do UniCEUB. Assessor de Planejamento e Estudos Estratégicos do CNPq. Pesquisador-orientador do projeto PIC-UniCEUB. Contatos por meio do e-mail: marcelog@cnpq.br.

${ }^{2}$ Graduanda em Relações Internacionais ( $8^{\circ}$ semestre) do UniCEUB. Bolsista do $6^{\circ}$ PIC/ UniCEUB. Esta pesquisa é parte do Projeto de Iniciação Científica (PIC-UniCEUB) intitulado A Biotecnologia Como Instrumento de Desenvolvimento Econômico e Social: A Conjuntura Brasileira e o Contexto Internacional.
} 
procedimentos científicos derivados de diferentes disciplinas como bioquímica, biologia molecular e celular (KREUZER; MASSEY, 2002).

Além dessas disciplinas, a biotecnologia engloba a engenharia química, ciências da computação, ciências materiais, genética, imunologia, fisiologia, microbiologia e engenharia bioquímica (COSTA, 2006). Portanto, a definição de biotecnologia evolui na medida em que seus protocolos, temas e áreas de pesquisa vão se refinando e se sucedendo ao longo do tempo. Um exemplo, de acordo com Valle (2005), são os temas "que há poucos anos suscitavam grande interesse e volume de pesquisas, como a fermentação e são gradativamente preteridos por novos temas e preocupações, como a genômica e a proteômica”.

Kreuzer e Massey (2002) afirmam que a biotecnologia é formada por um conjunto de habilidades tecnológicas produzido pelo conhecimento técnico e científico desenvolvido nessas diversas disciplinas. Os instrumentos biotecnológicos que pertencem a esse conjunto são: a tecnologia de anticorpos monoclonais, engenharia de proteínas, tecnologia do antisenso, tecnologia de bioprocessamento, tecnologia de biosensores, engenharia de tecidos, tecnologia de cultura de células e tecidos, engenharia genética e tecnologia de chip de DNA.

Para eles, esse conjunto variado é capaz de originar uma ampla gama de produtos e a maioria das aplicações comerciais dele reflete, principalmente, em três mercados: cuidados de saúde humana, gerenciamento ambiental e agricultura. A utilização deste instrumento tecnológico, portanto, proporciona a revolução em diversos aspectos da vida dos seres humanos e da relação destes com a natureza.

No campo da saúde, por exemplo, a biotecnologia é adotada como possível forma de diagnóstico, tratamento e prevenção de doenças. Na agricultura, desde o plantio das sementes até os alimentos que se encontram nos supermercados podem ser afetados por ela. O meio ambiente também pode sofrer a interferência da biotecnologia, pois ela é capaz de desvendar fontes novas e limpas de energia reciclável, novos métodos de detectar e tratar contaminações ambientais e desenvolver novos produtos e processos menos danosos ao ambiente do que os anteriormente utilizados (KREUZER; MASSEY, 2002).

Essas contribuições para a sociedade são frutos da revolução da informação tecnológica dos últimos anos que teve um papel importante na velocidade com a qual novas descobertas na biologia surgiram. 
Para que a aplicação da biotecnologia ofereça segurança à sociedade contra aos riscos inerentes às atividades investigativas e produtivas no campo, o seu desenvolvimento exige a criação de um ambiente institucional, necessita de uma forte base acadêmica e científica e um setor produtivo capaz de transformar essa produção acadêmica e científica em bens e serviços (SILVEIRA et al, 2004).

Tendo em vista as várias vantagens decorrentes da utilização da biotecnologia, o presente estudo versa sobre a sua utilização como alternativa para o Brasil suscitar maiores condições de inserção econômica e social. A biotecnologia vem gerando inovações tecnológicas, contribuindo para uma alta rotatividade de produtos no mercado, gerando competitividade empresarial e desenvolvimento socioeconômico.

Parece razoável afirmar que a capacidade técnico-científica de um país, cristalizada em sua capacidade de geração de novos produtos e serviços, é condição primária na arregimentação de condições de inserção econômica e desenvolvimento econômico e social.

Junto a isso, sendo o Brasil o país de maior patrimônio genético e biodiversidade no planeta, este artigo faz um desdobramento da maneira que o país está conduzindo sua política nacional de biotecnologia para compreender de que forma ele pode utilizar sua primazia no patrimônio genético e biodiversidade para alcançar uma posição privilegiada no cenário técnico-científico da biotecnologia.

Para tanto, fez-se um levantamento do cenário em que se encontra o desenvolvimento da biotecnologia nos Estados Unidos, país que ocupa a fronteira tenológica neste campo. Por meio da análise deste cenário, é possível identificar seus pontos positivos e compará-los com o Brasil para entender no que este último ainda pode acrescentar à sua política de inovação em biotecnologia.

A cooperação internacional também é abordada como canal facilitador para países em desenvolvimento, como o Brasil, obterem a transferência de tecnologia necessária para a aplicação da biotecnologia. Sua relevância neste trabalho está tanto no caminho que fornece para desenvolver políticas e ações entre os diversos atores presentes nas relações internacionais, bem como na sua forma de realização, que se dá em qualquer área do conhecimento humano. 


\section{Metodologia}

A metodologia desta pesquisa se restringiu à análise e revisão bibliográfica bem como na realização de entrevistas abertas a policy makers institucionais vinculados ao Conselho Nacional de Desenvolvimento Científico e Tecnológico (CNPq). A revisão bibliográfica relativa a temas como biotecnologia, organização da inovação, ambiente institucional, engenharia genética e regulamentação dos mercados, em âmbito nacional e internacional, foi realizada por meio de artigos, teses, dissertações, estudos e periódicos especializados, provenientes de fontes como o Departamento de Política Científica e Tecnológica da Universidade Estadual de Campinas; Ministério da Ciência e Tecnologia; Agência Brasileira de Cooperação, dentre outros. Para o marco teórico, utilizou-se Robert O. Keohane que, em Relações Internacionais, é conhecido por justificar a cooperação internacional por meio do institucionalismo neoliberal.

\section{Resultados}

Tendo em vista o teor qualitativo da pesquisa, não é possível demonstrar os resultados por meio de interpretações concretas como questionários. Desse modo, os resultados aqui apresentados são frutos de interpretações subjetivas que se originaram a partir dos objetivos específicos desta pesquisa:

- detalhar o campo da biotecnologia e sua importância transversal para o desenvolvimento científico, tecnológico e social;

- abordar as principais características e conjunturas da biotecnologia em países que ocupam a fronteira tecnológica neste campo; e

- comparar estas políticas e perspectivas face à política nacional de biotecnologia.

O primeiro objetivo foi mais bem esclarecido com a abordagem da biotecnologia e sua dinâmica. Constatou-se que diversos mercados como saúde humana, gerenciamento ambiental e agricultura podem obter benefícios com as aplicações da biotecnologia, o que reflete no bem-estar da sociedade. 
Atualmente, a biotecnologia é a tecnologia que apresenta maior compatibilidade com a sustentabilidade da vida neste planeta. Suas ferramentas são úteis na resolução de questões científicas, na elaboração de novos produtos e no alcance de metas desejadas pela sociedade, como na redução de poluição no meio ambiente.

A moderna biotecnologia adicionou precisão e rapidez ao desenvolvimento de novas variedades. Ao romper a barreira ao intercâmbio gênico imposta pelas espécies, anteriormente, era necessário promover o cruzamento entre organismos relacionados para obter uma característica desejada - a biotecnologia possibilita transferir genes entre espécies que não são compatíveis sexualmente, permitindo que as alterações no genoma $^{3}$ do organismo sejam previsíveis e precisas (Entendendo..., 2003).

Com as técnicas de engenharia genética, qualquer gene de qualquer organismo pode ser isolado e transferido para o genoma de qualquer outro ser vivo. Desse modo, é possível transferir para plantas, por exemplo, qualquer gene de peixes, ratos, humanos, bactérias ou vírus. Com efeito, os recursos genéticos para melhoramento de plantas e animais são ampliados, resultando na obtenção de plantas ou animais geneticamente modificados (organismos geneticamente modificados - OGMs).

No que diz respeito às práticas agrícolas mais ecológicas, o melhoramento genético é a alternativa ecologicamente mais equilibrada e de menor custo para o agricultor. Ao utilizar uma variedade melhorada, o agricultor contribui para o aumento da produção. Essa técnica é a mais promissora, precisa e rápida estratégia para elevar a produção agrícola mundial, reduzindo as perdas nas colheitas, decorrentes de pragas e doenças, e elevando a produtividade nas lavouras (Entendendo..., 2003).

No cenário brasileiro, a taxa de crescimento na agropecuária e as tecnologias em uso no país nos últimos 30 anos foram elogiadas por uma delegação da Agência Americana para o Desenvolvimento Internacional (USAID) e do Departamento de Agricultura dos Estados Unidos (USDA).

Os pesquisadores americanos assistiram a uma apresentação da evolução das pesquisas em melhoramento da soja e o uso de estirpes de bradyrizobium para fixação biológica do nitrogênio, pelos pesquisadores da unidade Cerrados, da Empresa Brasileira de Pesquisa Agropecuária (Embrapa).

\footnotetext{
${ }^{3}$ Genoma pode ser definido como um conjunto de genes de uma determinada espécie, presente em cada indivíduo.
} 
De acordo com o pesquisador Auteclínio Lopes de Farias Neto, a produção de soja no Cerrado representa 63,5\% do volume nacional. Os rendimentos da produção têm aumentado, em média $1,5 \%$ ao ano, ganhos que foram incorporados pelo melhoramento genético e às tecnologias desenvolvidas para reduzir custos e facilitar o manejo das lavouras (CIB, 2008).

Observa-se, portanto, que o estágio da biotecnologia moderna é extremamente relevante para alavancar o desenvolvimento de países em desenvolvimento como o Brasil. Desse modo, considerou-se importante definir, nesse ramo, a estratégia dos Estados Unidos, país que está na fronteira tecnológica, para suscitar novas políticas de biotecnologia para o Brasil.

Analisando a política de biotecnologia dos Estados Unidos, observou-se a partir do modelo "hélice tripla", que o arranjo institucional interno, que envolve a interação entre a universidade, a indústria e o governo, é fundamental para a inovação tecnológica de um país. Para países em desenvolvimento, por exemplo, investir nessa estrutura de três esferas faz com que eles passem a ter condições de empregar tecnologia inovadoras ao invés de depender da absorção de inovação gerada em países industrializados.

Se comparado a países desenvolvidos como os Estados Unidos, o Brasil ainda tem um pequeno investimento na geração de inovações, aplicando apenas $1,2 \%$ do seu PIB em ciência e tecnologia. Além disso, essa cooperação baseada no modelo "hélice tripla" ainda deixa a desejar. Sérgio de Castro Lessa, Coordenador e Analista em Ciência e Tecnologia do CNPq, afirmou em entrevista que o Brasil possui uma capacidade científica eficiente no desenvolvimento da biotecnologia. No entanto, o país apresenta dificuldades no que tange à interação entre as universidades e empresas, ou seja, a transformação do conhecimento em produto.

Percebe-se que a cooperação entre essas esferas tem-se dado muito mais pelo lado empresarial, de buscar nas universidades uma parceria tecnológica, do que pela oferta da tecnologia pela universidade. Diferentemente do que acontece nos Estados Unidos, as universidades ainda possuem uma postura tímida em relação à sua exposição no mercado consumidor, que no Brasil é constituído pelas empresas do setor público ou privado (PORTO, 2000). 
No entanto, o país tem tomado medidas para inovar nessa área. Prova disso é o Plano de Ação em Ciência, Tecnologia e Inovação para o Desenvolvimento Nacional 2007-2010 e a Política de Desenvolvimento de Biotecnologia e, ambos lançados pelo governo em 2007. Este último foi inspirado na Estratégia Nacional de Biotecnologia, resultado dos trabalhos realizados no âmbito do Fórum de Competitividade de Biotecnologia, instalado no final de 2004.

Entre os órgãos governamentais que fazem parte da coordenação desse projeto, estão o Ministério de Desenvolvimento, Indústria e Comércio Exterior, Ministério da Saúde, Ministério da Ciência e Tecnologia e Ministério da Agricultura, Pecuária e Abastecimento. Seu objetivo é:

Promover e executar ações com vistas ao estabelecimento de ambiente adequado para o desenvolvimento de produtos e processos biotecnológicos inovadores, estimular o aumento da eficiência da estrutura produtiva nacional, a capacidade de inovação das empresas brasileiras, absorção de tecnologias, a geração de negócios e a expansão das exportações (BRASIL, 2008b).

Detectou-se também que, por meio da cooperação internacional, o Brasil é capaz de se beneficiar com o modelo "hélice tripla". Prova disso é o Centro Brasil Argentina de Biotecnologia, $\mathrm{CBAB}$, que fortalece e promove o desenvolvimento da área de biotecnologia no Brasil e na Argentina mediante a promoção de cursos de curta duração e o apoio a projetos binacionais de pesquisa e desenvolvimento.

O Centro Brasil Argentina de Biotecnologia (CBAB/CABBIO) é um programa de integração regional que, desde sua constituição em 1986, tem colaborado para consolidar os laços de cooperação entre o Brasil e a Argentina, ampliando a base do conhecimento, de acordo com as necessidades e prioridades estabelecidas para a biotecnologia nos dois países (BRASIL, 2008a).

Os grupos de trabalho coordenados pelo $\mathrm{CBAB}$ envolvem os setores público e privado dos dois países. Os projetos são elaborados no âmbito binacional, nos quais se estabelece a complementaridade científica e tecnológica das duas nações. Vale ressaltar que, desde sua criação, o CBAB tem desenvolvido suas atividades de formar contínua, permanente e ininterrupta (ALVES et al, 2004). Com efeito, já foram investidos cerca de 5 milhões de dólares em ambos os países. 
Nesse sentido, a cooperação Sul-Sul mostrou-se relevante, uma vez que os países dessa região compartilham de problemas em comum. A cooperação Sul-Sul é uma estrutura ampla de colaboração entre países do Sul no âmbito político, econômico, social, ambiental e técnico. Conhecida também como cooperação tripartite, ou ainda, cooperação trilateral, a cooperação Sul-Sul é o suporte fornecido por países em desenvolvimento, com apropriada tecnologia em certas áreas, para os esforços de desenvolvimento de outros países da mesma categoria (JICA, 2008).

Esse tipo de cooperação se torna um instrumento eficaz para o desenvolvimento de países emergentes. Em tempos em que proliferam as barreiras comerciais discriminatórias, diminui a assistência ao desenvolvimento, aumenta a dívida externa dos países pobres e caem os preços das matériasprimas (DEEN, 2008).

Vale ressaltar, no entanto, que essa ferramenta não pode ser uma substituta das relações Norte-Sul, pois os países do norte são indispensáveis no fornecimento de inovações tecnológicas. A cooperação Sul-Sul serve, portanto, como instrumento de importância intrínseca ligada ao desenvolvimento e fortalecimento regional, uma vez que os países em desenvolvimento compartilham de problemas em comum.

Desse modo, a pesquisa mostra a importância da cooperação internacional para a absorção e, principalmente, troca de conhecimento e tecnologia entre os países. No entanto, ressalta que uma política nacional eficaz, que envolva a participação de universidade, empresa e governo, é necessária para que o Brasil possa se beneficiar do conhecimento que já existe, uma vez que agregar valor a esse conhecimento poderá promover o desenvolvimento econômico e social desejado.

\section{Conclusão}

A biotecnologia é uma área de grande potencial agregado, pois atua em diversos setores como saúde, agricultura, meio ambiente, entre outros. Sua importância para países em desenvolvimento é ilustrada pela capacidade que tem de promover o 
desenvolvimento nacional baseado no conhecimento e na inovação, com geração de empregos e suporte à economia.

A cooperação internacional, nesse contexto, é um processo de coordenação e negociação que viabiliza a transferência de conhecimento e tecnologia gerados no Brasil e no exterior. Por meio da troca de conhecimento entre os países, a biotecnologia se torna mais acessível e proporciona maiores vantagens a quem acolhe estas alianças.

Verificou-se neste relatório parcial que, mediante a nova Política de Desenvolvimento de Biotecnologia, o Brasil está ciente da importância desse instrumento tecnológico. Isso já é um ponto positivo para o país avançar nessa área e colher frutos no futuro.

As ações realizadas pelo Brasil no âmbito de cooperação bilateral, como o caso do Centro Brasileiro Argentino de Biotecnologia (CBAB), mostram que as alianças são um caminho que o Brasil deve relevar para obter melhor infraestrutura na realização de atividades relacionadas à biotecnologia.

O modelo "hélice tripla", parte da política de biotecnologia dos Estados Unidos, pode ser relacionado no escopo brasileiro, ao $\mathrm{CBAB}$ que, apesar das crises financeiras que encontrou desde sua criação, aponta muitas vantagens. O programa é um dos responsáveis pela construção da base biotecnológica no país, principalmente pela formação de recursos humanos de excelência, promovendo o intercâmbio científico entre diversas áreas.

No entanto, a pesquisa aponta a necessidade de uma verdadeira política administrativa pública brasileira, que não só defina melhor os objetivos e metas de programas como o $\mathrm{CBAB}$, bem como utilize de forma eficaz as parcerias entre universidades e empresas para que o conhecimento já existente tenha valor agregado a ele.

Desta forma, entende-se que acesso aos recursos financeiros, mais investimentos e maior incentivo a pesquisas são algumas das medidas que o Brasil poderia tomar para que a biotecnologia se torne um mecanismo de desenvolvimento econômico e social. 


\section{The biotechnology as a tool of economical and social development}

\section{Abstract}

This research intends to analyze the biotechnology as a source of social and economic development to Brazil. The International Cooperation is approached as a channel to obtain the necessary technological resources to use this tool. For this reason, it is performed an analysis of the International Technical Cooperation, one of the most important and evident streams of cooperation. The report points out that Brazil glimpses opportunities to urge its development throughout biotechnology with the recent Biotechnology Development Policy and the creation of the National Committee of Biotechnology. The analysis of the Brazilian Argentinean Biotechnology Centre (CBAB) empirically shows the importance of cooperation to stimulate the use of biotechnology in the South countries and, as a result, to accelerate the development in these places. However, the difficulty met by Brazil is in the absence of interaction among the academic and scientific sector and the productive sectors.

Keywords: Biotechnology. Development. International Cooperation. South-South Cooperation. Company-University Cooperation.

\section{Referências}

ALVES, T. G.; ROITMAN, C.; SOUZA-PAULA, M. C. Centro Brasileiro Argentino de Biotecnologia - CABBIO: 16 anos de atuação1987-2002. Brasília: CDS/UnB; MCT, 2004.

BRASIL. Ministério da Ciência e Tecnologia. Política de desenvolvimento da biotecnologia. Brasília, 2008. Disponível em:<http://www.mct.gov.br/upd_ blob/0016/16386.pdf>. Acesso em: 03 mar. 2008a.

BRASIL. Ministério do Desenvolvimento, Indústria e Comércio Exterior. Estratégia nacional de biotecnologia: política de desenvolvimento da bioindústria. Fórum de Competitividade em Biotecnologia. Brasília, 2006. Disponível em: <http://www2. desenvolvimento.gov.br/arquivo/sdp/20060705EstrategiaBiotecnologia.pdf >. Acesso em: 2 mar. 2008b.

CONSELHO DE INFORMAÇÕES SOBRE BIOTECNOLOGIA (CIB). Pesquisadores americanos elogiam evolução tecnológica da agropecuária brasileira. 
Disponível em: <http://www.cib.org.br/midia.php?ID=29475\&data=20080307>. Acesso em: 8 mar. 2008.

COSTA, E. T. Cooperação internacional em biotecnologia. 2006. 78 p. Trabalho de conclusão de curso (Graduação)-Centro Universitário de Brasília, Brasília, 2006.

DEEN, Thalif . Cooperação sul-sul é o caminho do futuro. IPS, Doha, jun. 2005. Disponível em: <http://mwglobal.org/ipsbrasil.net/nota.php?idnews=683>. Acesso em: 4 mar. 2008

ENTENDENDO A BIOTECNOLOGIA. Viçosa: Agromídia Software Ltda, [2003]. CD-ROM.

JICA. Home page. Tokyo, 2008. Disponível em:<http://www.jica.org.br/br/ cooperacao_sulsul/oquee.htm>. Acesso em: 4 mar. 2008.

KREUZER, H.; MASSEY, A. Engenharia genética e biotecnologia. Porto Alegre: Artmed, 2002.

PORTO, G. S. A decisão empresarial de desenvolvimento por meio da cooperação empresa-universidade. 2000. Tese (Doutorado em Administração)-Faculdade de Economia, Administração e Contabilidade, Universidade de São Paulo, São Paulo, 2000.

SILVEIRA, J. et al. Evolução recente da biotecnologia no Brasil. Campinas, SP: Instituto de Economia. Universidade Estadual de Campinas, 2004. (Texto para Discussão, $n^{\circ} 114$ ).

VALLE, M. G. O sistema nacional de inovação em biotecnologia no Brasil: possíveis cenários. 2005. 249 f. Tese (Doutorado em Política Científica e Tecnologia)Instituto de Geociências, Universidade Estadual de Campinas, Campinas, 2005. 